\title{
Genotype x Environment Interactions, Adaptability with Sustainability Index and their Comparison in Release Varieties of Sugarcane (Saccharum officinarum L.) under South Eastern Plain Zone of Rajasthan
}

\author{
N. R. Koli*, R. K. Meena, Manoj Kumar, P. K. P. Meena, S. N. Meena and R. S. Jatav \\ Agricultural Research Station, Ummedganj, Kota-324001, \\ (Agriculture University, Kota), India \\ *Corresponding author
}

\section{A B S T R A C T}

\section{Keywords \\ G X E interaction, regression coefficient (bi), Deviation from regression $\left(S^{2} d\right)$, Sustainability index in popular varieties of sugarcane}

\section{Article Info}

Accepted:

15 July 2020

Available Online:

10 August 2020
Seven release varieties of sugarcane (Saccharum officinarum L.) were evaluated for G X E interaction, adaptability with sustainability index and their comparison for cane yield $(\mathrm{t} / \mathrm{ha})$ incomplete randomized block design during spring season of 2015-16, 2016-17, 2017-18, 2018-19 \& 2019-20 at Agricultural Research station, Ummedganj, Kota under SouthEastern Plane Zone of Rajasthan. The mean cane yield ( $\mathrm{t} / \mathrm{ha}$.), regression coefficient (bi) and deviation from regression $\left(S^{2} d\right)$ with sustainability index was used to identify the stability and adaptability of popular sugarcane varieties. Pooled analysis of variance showed highly significant differences among environments, genotypes and genotype $\mathrm{x}$ environment $(G \times E)$ interaction. Sufficient mean square values due to $G \times E$ interactions indicated the varieties interacted considerably with the environmental conditions. Both linear and nonlinear components of $\mathrm{G}$ x E (linear) components were highly significant showing the importance in expression of traits. The linear component was significant as against the nonlinear component (Pooled deviation), which revealed that a large portion of $\mathrm{G} \times \mathrm{E}$ interaction was accounted for by the linear regression through pooled deviation was significant. Based on stability parameters and over all mean performance of cane yield, variety Co $0238, \operatorname{CoS} 8436$ and Co pant 97222 were identified as superior which were well adapted to all the environments, stable with above average yielding ability or highest Cane yield with non-significant bi and $\mathrm{s}^{2} \mathrm{~d}$ values coupled with high sustainability index. This showed that these varieties were better responsive to the favorable environments. Variety CoJ 64 \& Co 05009 was responded favourable to better environments but give poor yield in unfavorable environments. Hence, they are suitable for favorable environments.

\section{Introduction}

Sugarcane is one of the major cash crops grown extensively in all over the world from tropical to subtropical region. India is the second largest producer in the sugarcane next to Brazil (FAO Data base 2004). Generally, sugarcane is vegetatively cultivated crop with widely adapted and diversity. In sub-tropical India, variation in climatic conditions are wide in the period of its growth and maturity, here, temperature ranges from 0 to $48^{\circ} \mathrm{C}$, 
photoperiod ranges from 4-8 h, humidity 8$100 \%$. Climatic coefficient shifts are variable factors during the crop growth period which affect the yield and other characters of the crop. Hence the yield of sugarcane is generally low in this part of India. Sugarcane breeding is highly complex because of its highly heterozygous nature, combined with higher polyploidy level $(2 n=80$ to 120$)$. Genotype $\mathrm{x}$ Environment interactions are important source of variation in any crop and the term stability is sometimes used to characterize a genotype, which show a relatively constant yield, independent of changing environmental conditions. On the basis of this idea, genotype with a minimal variance for yield across different environments is considered stable (Sabaghnia et al., 2006). The analysis of adaptability and stability are therefore extremely important and necessary for the identification and recommendation of superior genotypes in different environments. Therefore, it is necessary to evaluate genotype for $\mathrm{G} \times \mathrm{E}$ interaction for yield and its attributes and identify stability for these traits in sugarcane. Cane yield and its component traits are highly affected by the environments. Techniques for $\mathrm{G} \times \mathrm{E}$ analysis based on linear regression can be informative when $\mathrm{G} \times \mathrm{E}$ interaction has high linear association with the environmental index but when the non linear component is also significant (Finley and Wilkinson 1963 and Varma et al., 2007). The analysis based on Eberhart and Russell model being relatively simple has been widely used for stability analysis. Estimation of $G \times E$ interaction consists of complementary procedures classification and grouping the genotypes according to their response in different environments (Singh and Agrawal 2003). Genotype and environment interaction is important in understanding the stability in cane yield of a particular genotype before is being recommended for a given situation (Varma et al., 2013). Regarding in stability parameters, sufficient information is not available in sugarcane which could be used in further breeding programme. Keeping above facts in view, the present investigation was under taken to evaluate Genotype $\mathrm{x}$ Environment interaction and stability analysis for cane yield and its component traits of well adapted popular sugarcane varieties.

\section{Materials and Methods}

The present experiment was carried out with seven release varieties of sugarcane namely, CoJ 64, Co 0238, Co 05009, CoS 767, CoS 8436 Co Pant 97222 and Co 05011 in different environment to test stability. The experiment were laid out in complete randomized block design with three replications with row to row spacing of 90 $\mathrm{cm}$. during spring season of five years (201516, 2016-17, 2017-18, 2018-19 and 2019-20) at Agricultural Research Station, Ummedganj, Kota, Rajasthan and recommended agronomic practices were followed during the entire cropping season to ensure good crop. The stability of genotypes/varieties was estimated by using the method of Eberhart and Russell (1966). In this analysis sum of square due to $\mathrm{G} \times \mathrm{E}$ were portioned into individual genotype, regression of environmental mean (bi) and deviation from regression $\left(\mathrm{S}^{2} \mathrm{~d}\right)$. The regression coefficient (bi) and mean square deviation from regression $\left(\mathrm{S}^{2} \mathrm{~d}\right)$ were used to define genotype stability. The pooled error was used to test the hypothesis that the mean square deviation did not differ significantly from 0.05 and $0.01 \%$ probability levels. The t-test employing the standard error of regression coefficient against the hypothesis that it did not differ from 1.0 it was assumed that genotype effects were fixed and the year effects were random. The data on cane yield was recorded on plot basis and estimated in $\mathrm{t} / \mathrm{ha}$. The five years data on each variety were used for estimation of stability parameters by using the Eberhart and Russell (1966) model 
and sustainability index was estimated according to following formula used by other workers (Singh and Agarawal, 2003; Gangwar et al., 2004).

Sustainability index (S.I. $)=(\mathrm{Y}-$ Ón $) / \mathrm{Y}_{\mathrm{M}} \mathrm{X}$ 100

Where, $\mathrm{Y}=$ Average performance of a genotype, Ón = standard deviation and

$\mathrm{Y}_{\mathrm{M}}$ = Best performance of a genotype in any year.

The value of sustainability index was arbitrarily divided in to five group viz. very low (up to 60\%), low (61- $70 \%$ ), moderate (71-80\%), high (81-90) and very high (above $90 \%)$

The cane yield differences were found to be significant over five years, indicating genetic difference among the varieties tested under the study. For drawing meaningful interference, the cane yield (best performance) and sustainability index could be divided into four groups as follows;

\begin{tabular}{|l|l|l|}
\hline $\begin{array}{l}\text { Yield (Best } \\
\text { Performance) }\end{array}$ & $\begin{array}{l}\text { Sustainability } \\
\text { index }\end{array}$ & Remarks \\
\hline High & High & Desirable \\
\hline High & Low & $\begin{array}{l}\text { Location } \\
\text { specific }\end{array}$ \\
\hline Low & High & Undesirable \\
\hline Low & Low & Undesirable \\
\hline
\end{tabular}

\section{Results and Discussion}

Pooled analysis of variance (Table 1) showed that genotype, environment and genotype $\mathrm{x}$ environment interaction ( $\mathrm{G} \times \mathrm{E}$ ) were highly significant for all the variables revealing the presence of sufficient variability in the materials. Significant mean squares due to genotype $\mathrm{x}$ environment interactions indicated differential response of genotypes in different environments. It means a particular variety may not exhibit the same phenotypic performance under different environments or different varieties may respond differently to a specific environment. Significant genotypic interaction with environments was earlier reported by Koli et al., 2016 in sugarcane. Both linear and non-linear components of $\mathrm{G} \mathrm{x}$ $\mathrm{E}$ interactions were also found significant for cane yield showing the importance of both linear (predictable) and non-linear (unpredictable) components in the expression of the traits. The linear component was significant as against the nonlinear components (Pooled deviation), which revealed that a large portion of $G \times E$ interaction was accounted for by linear regression although pooled deviation was significant. These results were in confirmation to those reported by Kimberg et al., 2009, Tiwari et al., 2011, Koli et al., 2016 and Naidu et al., 2017 in sugarcane.

Eberhart and Russell (1966) defined a stable genotype as the one which showed high mean yield, regression coefficient (bi) around unity and deviation from regression near to zero. Accordingly, the mean and deviation from regression of each variety were considered for stability and linear regression was used for testing the varietal response.

Genotypes with high mean, bi = 1 with non significant $\mathrm{s}^{2} \mathrm{~d}$ are suitable for general adaption, i.e. suitable over all environmental conditions and they are considered as stable genotype.

Genotypes with high mean, bi $>1$ with non significant $\mathrm{s}^{2} \mathrm{~d}$ are considered as below average in stability. Such genotypes tend to respond favourably to better environments but give poor yield in unfavourable environments. Hence, they are suitable for favorable environments.

Genotypes with low mean, bi<1 with non significant $\mathrm{s}^{2} \mathrm{~d}$ do not respond favourably to improved environmental 
conditions and hence, it could be regarded as specifically adapted to poor environments.

Genotypes with any bi value with significant $\mathrm{s}^{2} \mathrm{~d}$ are unstable.

In the present study, promising varieties Co 0238 and Co Pant 97222 were having high mean cane yield with bi $=1.0$ and nonsignificant $\mathrm{s}^{2} \mathrm{~d}=0$ (Table 2), indicated that these two varieties were better responsive to all the environments and were considered as stable varieties. CoJ 64 and Co 05009 produced above average yield with nonsignificant unit regression value and deviation from regression (0), indicated below average stability, such genotypes tend to respond favourably to better environments but give poor yield in unfavourable environments. Hence, these genotypes were suitable for favorable environments. Variety $\operatorname{CoS} 8436$ having low mean, bi $=1$ with nonsignificant $\mathrm{s}^{2} \mathrm{~d}$ value, indicated that genotype suitable for poor environment or poorly adopted in all environment.

Table.1 Pooled analysis of variance for cane yield ( $\mathrm{t} / \mathrm{ha}$ ) of popular sugarcane varieties in South Eastern Plain Zone of Rajasthan

\begin{tabular}{|l|c|c|}
\hline Source of Variation & Degree of Freedom & Mean sum of squares \\
\hline Total & 34 & $51.616^{* *}$ \\
\hline Genotype & 6 & $154.221^{* *}$ \\
\hline Environment & 4 & $28.611^{* *}$ \\
\hline GXE & 24 & $8.681^{* *}$ \\
\hline E + (G X E) & 28 & $4.191^{*}$ \\
\hline E linear & 1 & $5.450^{*}$ \\
\hline G X E Linear & 6 & $7.092^{*}$ \\
\hline Pooled Deviation & 21 & $3.302^{* *}$ \\
\hline Pooled Error & 60 & $0.170^{* *}$ \\
\hline
\end{tabular}

*,** Significant at $5 \%$ and $1 \%$ level of probability

Table.2 Stability parameter for grain yield (t/ha) of popular sugarcane varieties in Zone $\mathrm{V}^{\text {th }}$ of Rajasthan

\begin{tabular}{|l|l|c|c|c|}
\hline S.No. & Name of Varieties & $\begin{array}{c}\text { Mean Cane Yield } \\
\text { (t/ha.) }\end{array}$ & $\begin{array}{c}\text { Regression } \\
\text { Coefficient } \mathbf{( b i )}\end{array}$ & $\begin{array}{c}\text { Deviation from } \\
\left.\text { regression } \mathbf{( S}^{-\mathbf{d}} \mathbf{d}\right)\end{array}$ \\
\hline $\mathbf{1 .}$ & CoJ 64 & 76.38 & 1.7220 & 2.081 \\
\hline $\mathbf{2 .}$ & Co 0238 & 83.05 & 1.0221 & -0.177 \\
\hline $\mathbf{3 .}$ & Co 05009 & 79.64 & 1.6940 & 2.651 \\
\hline $\mathbf{4 .}$ & CoS 767 & 79.44 & 0.3459 & -2.641 \\
\hline $\mathbf{5 .}$ & CoS 8436 & 73.83 & 0.9147 & -0.901 \\
\hline 6. & Co Pant 97222 & 75.91 & 0.9014 & -1.455 \\
\hline 7. & Co 05011 & 75.17 & 0.3999 & -0.284 \\
\hline
\end{tabular}


Table.3 Estimates of sustainability index (\%) for Cane yield ( $\mathrm{t} / \mathrm{ha}$ ) of popular sugarcane varieties

\begin{tabular}{|l|l|c|c|c|c|}
\hline S.No. & \multicolumn{1}{|c|}{$\begin{array}{c}\text { Name of } \\
\text { Varieties }\end{array}$} & $\begin{array}{c}\text { Mean Cane Yield } \\
\text { (t/ha.) }\end{array}$ & $\begin{array}{c}\text { Standard } \\
\text { Deviation(on) }\end{array}$ & $\begin{array}{c}\text { Best Performance } \\
\text { of genotype in any } \\
\text { year }\left(\mathbf{Y}_{\mathbf{M}}\right)\end{array}$ & $\begin{array}{c}\text { Sustainabil } \\
\text { ity Index } \\
\mathbf{( \% )}\end{array}$ \\
\hline $\mathbf{1 .}$ & CoJ 64 & 76.38 & 2.86 & 82.22 & 91.07 \\
\hline $\mathbf{2 .}$ & Co 0238 & 83.05 & 1.96 & 87.56 & 94.22 \\
\hline $\mathbf{3 .}$ & Co 05009 & 79.64 & 2.91 & 84.17 & 93.41 \\
\hline $\mathbf{4 .}$ & CoS 767 & 79.44 & 0.86 & 84.35 & 97.37 \\
\hline $\mathbf{5 .}$ & CoS 8436 & 73.83 & 1.74 & 78.90 & 95.51 \\
\hline $\mathbf{6 .}$ & Co Pant 97222 & 75.91 & 1.60 & 81.22 & 94.68 \\
\hline $\mathbf{7 .}$ & Co 05011 & 75.17 & 1.60 & 80.25 & 94.89 \\
\hline
\end{tabular}

Table.4 Comparison between the Eberhart and Russell model of stability and Sustainability index

\begin{tabular}{|l|l|c|c|c|c|c|c|}
\hline S.No. & \multicolumn{1}{|c|}{$\begin{array}{c}\text { Name of } \\
\text { Varieties }\end{array}$} & $\begin{array}{c}\text { Mean Cane } \\
\text { Yield (t/ha.) }\end{array}$ & \multicolumn{2}{|c|}{ Eberhart and Russell model } & \multicolumn{2}{|c|}{ Sustainability Index (\%) } \\
\hline 1. & CoJ 64 & 76.38 & 1.7220 & 2.081 & Stable & 91.07 & Vary high \\
\hline 2. & Co 0238 & 83.05 & 1.0221 & -0.177 & Stable & 94.22 & Vary high \\
\hline 3. & Co 05009 & 79.64 & 1.6940 & 2.651 & Stable & 93.41 & Vary high \\
\hline 4. & CoS 767 & 79.44 & 0.3459 & -2.641 & Stable & 97.37 & Vary high \\
\hline 5. & CoS 8436 & 73.83 & 0.9147 & -0.901 & Stable & 95.51 & Vary high \\
\hline 6. & Co Pant 97222 & 75.91 & 0.9014 & -1.455 & Stable & 94.68 & Vary high \\
\hline 7. & Co 05011 & 75.17 & 0.3999 & -0.284 & Stable & 94.89 & Very high \\
\hline
\end{tabular}

Sustainability index was also used to identify the stable genotypes. The average cane yield $\left(\mathrm{Y}_{\mathrm{M}}\right)$, standard deviation (Ón) and sustainability index (SI \%) of each genotype has been given in Table 3. High sustainability index $(\%)$ was observed in all the varieties of sugarcane. The best performance coupled with high value of sustainability index could be taken as the indication of close proximity between the best performance and the average performance over the years, which indicated that, this chapter is least influenced by the environmental factors. Similar findings were earlier reported by Imtiaz et al., (2013), Kumar et al., (2004), Guddadamath et al., (2014) and Naidu et al., 2017 in sugarcane.

The comparison of Eberhart and Russell (1966) model with new model based on sustainability index are presented in Table 4 contradict with respect to the stability parameters and the sustainability index.

In present study, Eberhart and Russell model was found to be more robust for predicting the stable genotypes. The stable genotype with respect to the cane yield under variable environments may be useful in breeding programme for evolving high yielding genotypes adapted in this zone. On the basis of these results, says that, varieties Co o238 and Co pant 97222, CoJ 64 and Co 05009 are suitable for commercial cultivation in the Humid-South-Eastern plan Zone of Rajasthan.

\section{Acknowledgement}

The first author is grateful thank to Director Research, Agriculture University, Kota, Zonal Director Research, ARS, Kota, and also 
grateful thanks to Project Coordinator, IISR, Lucknow, for providing necessary facilities and financial support to conduct the research work.

\section{References}

Eberhart S A and Russell W L. 1966. Stability parameters for comparing varieties. Crop Sci. 6:36-40.

FAO. Data base, 2004. Area, production and yield of major sugar cane producing countries. http://www2.biodiversity international.org/publications/pgrnewsl etter/tables/table4-148.htm.

Finley K W and Wilkinson G E. 1963. The analysis of adaptation in a plant breeding programme. Australian journal of Agricultural Research 14:742-54.

Gangwar B, Katyal V and Anand K V. 2004. Stability and efficiency of cropping system in Chhattisgarh and Madhya Pradesh. Indian Journal of Agricultural Sciences 74:521-8

Guddaamath S. G. Patel S B. and Khadi B M. 2014. Stability and regression analysis in elite genotypes of sugarcane (S.spp. hybrid complex). African journal of Agriculture Research. 9 (37): 28462853.

Imtiaz A K., Nighat S., Raza S., Yasmine S and Sajida B. 2013. Environmental interaction of sugarcane genotype and yield stability analysis of sugarcane. Pak. Journal of Bot., 45 (5): 1617-1622.

Kimberg C A., Zhoul M M and Dasiuva 2009. Genotype $\mathrm{X}$ environment interaction and resources allocation in sugarcane yield traits in the Rio-Grande valley region of Texas. Journal of American Society of Sugarcane technologist. 29:11-24.

Kumar S., Sigh P K., Singh J. and Swapna M. 2004. G x E interaction analysis for quantitative traits in sugarcane. Indian
Sugar 13 (10): 813-818.

Koli, N. R., Bagri, R. K., Meena, B. S. and Kumhar B.L. 2016. Studies on stability parameter and sustainability index for selecting stable genotypes of sugarcane (Saccharum officinarum L.). Electronic journal of Plant Breeding 18(1): 137139.

Naidu, P. N., Khan, M. G. M. and Jokhan A.D. 2017. Assessment of sugarcane varieties for their stability and yield potential in Fiji. The South Pacific Journal of Natural and Applied Sciences. 31(2): 20-32.

Sabaghnia, N., Dehghani H. and Sabaghpour S.H. 2006. Non parametric methods for interpreting genotype $\mathrm{x}$ environment interaction of lentil genotypes. Crop sci., 46: 1100- 1106.

Singh P. and Agarwal D.K. 2003. Sustainability index as an aid for determining the genotypic stability in diploid cotton. Journal of Cotton Research Development 17 (1): 90-2.

Tiwari D K., Panday P, Singh R K., Singh S P and Singh S B. 2011. Genotype $\mathrm{X}$ environment interaction and stability analysis in elite clones of sugancane $(S$. officinarum L.). International Journal of Plant Breeding and Genetics 5 (1): 93-98.

Verma S K. Tuteja O P, Koli N R, Singh Jal, Ram Niwas and Monga D. 2007. Assessment of genotype $\mathrm{x}$ environment interaction for diverse set of cotton $(G$. arboretum L.) of various ecogeographic regions evaluated under North Indian conditions. Indian Journal of Agricultural Sciences. 77 (4):258-60.

Verma S K. Tuteja O P and Monga D. 2013. Studies on stability parameters and sustainability index for selecting stable genotypes in Asiatic cotton ( $G$. arboretum L.). Indian Journal of Agricultural Sciences. 83 (12):1377-80. 


\section{How to cite this article:}

Koli, N. R., R. K. Meena, Manoj Kumar, P. K. P. Meena, S. N. Meena and Jatav, R. S. 2020. Genotype $\mathrm{X}$ Environment Interactions, Adaptability with Sustainability Index and their Comparison in Release Varieties of Sugarcane (Saccharum officinarum L.) under South Eastern Plain Zone of Rajasthan. Int.J.Curr.Microbiol.App.Sci. 9(08): 1143-1149. doi: https://doi.org/10.20546/ijcmas.2020.908.126 